\title{
«Tantó por plumas...» Góngora y los poetas cordobeses del Siglo de Oro
}

\section{Antonio Cruz Casado}

Arbor CLXVI, 654 (Junio 2000), 277-295 pp.

«jOh siempre gloriosa patria mía Tanto por plumas cuanto por espadas! 1

Góngora

\section{Introducción}

A la amplia tradición de los ilustres capitanes cordobeses, simbolizada por las espadas, une Góngora, en un conocido soneto, la relevancia cultural, humanística y literaria de su ciudad natal, sugerida mediante la designación plumas. Aunque la alabanza a cualquier ciudad o nación, basada en la importancia de su pasado cultural o militar, o en las aportaciones que ha ido realizando a lo largo de los siglos en cualquier aspecto de la creatividad humana, suele ser un tópico más o menos generalizado, en Córdoba se localiza de manera efectiva una brillante trayectoria que abarca diversas culturas antiguas y que se desarrolla a lo largo de los siglos, tal como se ha puesto de relieve en una acertada antología literaria ${ }^{2}$, que incluye textos de poetas cordobeses de la época romana, la árabe y la judaica, además de la cristiana o más propiamente hispánica. Se constata una notoria acumulación de grandes figuras cordobesas en esas culturas, entre las que se pueden mencionar a Séneca y a Lucano, a Averroes y a Ibn Hazam, a Juan de Mena y a Góngora, en tanto que en los siglos posteriores parece decaer algo el elevado nivel alcanzado por las personalidades mencio- 
nadas, sin que ello sea óbice para que todavía se encuentren cualificados representantes cordobeses en el ámbito de la cultura, como el Duque de Rivas, en el período romántico, o el egabrense don Juan Valera, en la segunda mitad del XIX. Por lo que respecta al siglo XX, es posible que aún carezcamos de la perspectiva necesaria para determinar la aportación de Córdoba a la cultura literaria de esa centuria, pero sin duda fue una aportación importante la labor de los poetas del grupo «Cántico», en el pobre panorama de la posguerra española, así como la de otras figuras sueltas que afloraron en la segunda mitad del siglo.

De la importancia de don Luis de Góngora y Argote, en el contexto literario de su momento (con razón llamado Siglo de Oro de nuestra cultura), dan fe numerosas ediciones y estudios, incluso traducciones recientes, que lo hacen hablar en lenguas tan exóticas como el japonés ${ }^{3}$, de tal manera que su figura se agiganta con el paso del tiempo, convirtiéndose en lo que Cervantes decía, un tanto benévolamente, de otro notable aunque preterido poeta cordobés (el lucentino Luis Barahona de Soto), que era en su opinión «uno de los grandes poetas del mundo, no sólo de España» ${ }^{4}$.

No queremos insistir de manera especial en la profunda revolución que supuso la poesía gongorina en las primeras décadas del siglo XVII, de lo que algo había barruntado ya, en cierto sentido, el propio poeta al indicar que era consciente de que había «dado principio a algo» ${ }^{5}$, puesto que todo ello pertenece a lo más conocido de nuestro pasado literario; tampoco vamos a hablar de las intercadencias de la crítica con respecto a los valores que introdujo Góngora en la creación lírica, no siempre aceptados ni comprendidos. Como se señala con alguna frecuencia, el redescubrimiento del escritor en el siglo XX se achaca al grupo poético del 27, que toma su denominación específica de la conocida efemérides gongorina (el tercer centenario de su muerte), y su rescate y puesta en valor se deben a la ejemplar y nunca lo bastante encomiada labor crítica de Dámaso Alonso ${ }^{6}$. Todo ello viene a ser cierto en líneas generales, y como tal suele ser aceptado, aunque en esta línea de revalorización de don Luis se ha solido silenciar la positiva labor que en su momento llevó a cabo la Real Academia de Córdoba, en lo que se refiere a la difusión de la figura y la obra del poeta cordobés con motivo del mencionado tercer centenario ${ }^{7}$. En la actualidad don Luis de Góngora y Argote nos parece un valor seguro y prácticamente inamovible, pero para resaltar más la especificidad de su obra puede resultar esclarecedor trazar un esbozo de la poesía y la erudición cordobesa de su época, sobre la que se proyecta su perfil luminoso, a la 
«Tanto por plumas...» Góngora y los poetas cordobeses...

manera de una efigie central que se alza recortada contra un fondo grisáceo, paisaje cultural y humano aparentemente integrado por figuras desvaídas y brumosas.

Lo que sí parece cierto es que la poesía que le procuró al escritor honra y fama, no trajo consigo ganancias especiales ni prebendas que le hiciesen pasar su vejez con una pasable dignidad y decoro. De ello es testigo su epistolario personal, plagado de peticiones de dinero a su administrador de rentas así como de referencias a su mala situación. Así, el día primero de enero de 1619 terminaba Góngora su carta, fechada en Madrid y dirigida a su amigo y benefactor don Francisco del Corral, con las siguientes palabras: "Yo estoy sin un cuarto, y sin auctoridad, que es lo peor, para buscarlo» ${ }^{8}$. La reiteración de esta queja es una constante a lo largo del epistolario gongorino, en un arco temporal que abarca aproximadamente los diez últimos años de su vida, desde 1617 hasta 1626. Las necesidades económicas del pretendiente en la corte son cada vez más perentorias, pendiente siempre del dinero que le manda su administrador, el licenciado Cristóbal de Heredia, y que le llega casi siempre tarde, cuando ya ha contraído nuevas deudas, superiores a los mil reales mensuales de su pensión. Los acreedores del escritor no esperan y el crédito de Góngora se resiente. De esta manera es posible que incluso padeciese algún tipo de necesidad física, como se manifiesta en la carta de fin de año del 1619 al mismo don Francisco: «Mi señor y amo, acá se pasa muy trabajosamente viendo comer a otros. Mañana entra enero, que da principio al año y a mis alimentos. Sírvase V. m. de solicitar de nuestro Cristóbal me libre dos meses, que es mi verdad no tengo para aderezar con ellos el coche» (p. 949). Como vemos don Luis termina el año en la misma situación que lo empezó.

La penuria va a ser muy frecuente porque, como hemos visto en la última cita, el coche, la apariencia, es una necesidad ineludible en el mundo de la época, superior, según se deduce de diversos textos, a la necesidad de comida: "Mis incomodidades son mayores cada día -escribe a su amigo el 14 de julio de 1620-, porque crecen, como las sombras a las declinaciones, a las omisiones de Cristóbal de Heredia: no hay luz ni aun crepúsculo de comodidad; noche es en la que vivo, y, lo que peor es, sin tener que cenar en ella...» (p. 964). En ocasiones la amarga ironía se hace patente en su correspondencia: «Nuestro amigo - se refiere al mismo Heredia en carta del 16 de febrero de 1621- hace experiencias costosas de mi naturaleza, averiguando sin duda lo que tengo de angélico, pues me deja ayuno tantos días. Sírvase V. m. de suplicalle de mi parte no dilate lo que tanto importa a mi 
autoridad, que estoy de manera que tengo vergüenza hasta de decir lo que debo y solo tengo de término este mes de febrero con mis acreedores» (p. 978). Los mismos términos emplea en sus cartas a Heredia: «Más embarazado estoy que quisiera-le escribe el 31 de mayo de 1622- y más sin dinero que he estado, pues le juro a fe de cristiano, que me hallo hoy, último de mayo, con solos nueve reales» (p. 1023), Alguna vez la desesperación del hombre sin dinero adquiere tintes dramáticos: "Ahora, señor, tomo la pluma por no tomar una soga que acabe con todo y deje descansar a Vuestra merced de mis pesadumbres —escribe a Heredia el 11 de julio de 1623-. Con ella suplico a Vuestra merced se sirva de considerar que de 800 reales no se puede pagar casi ni vestir mi persona ni las de dos pajes, sustentar dos criadas tan honrada una como María Rodríguez, y mantener un coche que me trae arrastrado» (pp. 1045-1046). Los ejemplos de este tipo podrían multiplicarse ampliamente ${ }^{9}$.

Claro que, a pesar de esta segura pobreza, Góngora contaba con admiradores, protectores y amigos, que se constituyeron en una especie de escudo o salvaguarda cuando los ataques de los detractores de las Soledades arreciaron, amenazando con ridiculizar hasta extremos insospechados una aportación lírica que se consideraba en su momento tan sumamente original y trascendente que algunos devotos del poeta llegaron a equipararlo públicamente con Homero, tal como se ve en la portada de la primera edición de sus obras: Obras en verso del Homero español (1627). El nombre auténtico del poeta no figura en esta portada, pero cualquier lector más o menos al tanto de su momento cultural sabría a quien se estaba refiriendo el editor Juan López de Vicuña.

Una idea de la actividad cultural de la ciudad en los siglos áureos la proporciona el número de ediciones que dan a luz las prensas cordobesas. Según el recuento de Valdenebro, en los ciento cincuenta años que abarca su catálogo ${ }^{10}$ para estas centurias, a partir de 1556, aparecen contabilizados casi tres centenares de impresos de diversa entidad, aunque muchos de ellos corresponden a libros religiosos y morales $o$ bien a pliegos sueltos y relaciones de ciegos. Es cierto que aparecen textos de reconocida importancia histórica o literaria, como la Crónica de Ambrosio de Morales, en 1586, o las Obras del maestro Hernán Pérez de Oliva, en la mișma fecha, pero apenas se constatan libros de poesía o de amena literatura, de tal manera que en vida de Góngora sólo puede citarse la edición de las Rimas de Antonio de Paredes (1623) y, en fecha cercana, las Varias rimas de Miguel Colodrero de Villalobos (1629). Con todo, y a pesar de esta aparente escasez, los indicios más 
«Tanto por plumas...» Góngora y los poetas cordobeses...

ciertos de una notable actividad lírica la ofrecen las celebraciones varias en las que se incluyen certámenes poéticos, de lo que son buena muestra las Honras que se hicieron a la muerte de la reina doña Margarita de Austria (1612), las Fiestas a la beatificación de Santa Teresa (1615), que contaron con la intervención de Góngora, y, más tardíamente, las Fiestas al Ángel Custodio San Rafael (1653).

Limitándonos a los dos primeros festejos señalados, podemos indicar que, en el certamen poético por la reina Margarita ${ }^{11}$, figuran diversos representantes de lo que pudiéramos llamar la intelectualidad cordobesa, encabezados por Góngora, pero donde se encuentran también Pedro de Cárdenas y Angulo, Antonio de las Infantas, el delicado poeta extremeño Antonio de Paredes, tan ligado a nuestra ciudad, el médico Enrique Vaca de Alfaro, o Basilio Vaca, junto con los religiosos fray Hernando de Luján, mercedario, y fray Andrés Márquez, agustino. Además de las composiciones castellanas se incluyen también poemas y jeroglíficos latinos; todos ellos habían servido para adornar «en bien cortadas tarjetas» el túmulo real levantado en Córdoba a la memoria de la fallecida. El conjunto da una impresión de buena calidad, a pesar de la obvia reiteración del tema e incluso de los estilemas alusivos a las perlas que sugieren el nombre de la reina. Góngora, considerado ya en este momento uno de los poetas fundamentales del período, que pronto divulgaría entre sus amigos y en los círculos cortesanos la Soledad primera, encabeza el librito con tres sonetos, a lo que añade luego una estancia y dos décimas; el noble y protector de don Luis, don Pedro de Cárdenas y Angulo, participa con dos sonetos, Vaca de Alfaro con otros dos y una décima, Antonio de Paredes con una mediana colección de diez sonetos.

Más amplio es el certamen dedicado a Santa Teresa ${ }^{12}$, subdividido en nueve apartados de acuerdo con la métrica impuesta, y aquí se traspasa el nivel localista, puesto que en la recopilación que lleva a cabo Juan Páez de Valenzuela, figuran poetas de Córdoba y su provincia, pero también muchos otros andaluces, procedentes de Jaén o de Antequera. Entre los numerosos nombres se incluyen algunos de los antes citados, como don Luis de Góngora, con un romance, Enrique Vaca de Alfaro, que obtiene un premio en el segundo certamen, o Antonio de Paredes, junto con otros poetas y eruditos de su círculo inmediato, entre los que figuran José Pérez de Ribas y Pedro Díaz de Ribas. Con respecto a los poetas procedentes de otros lugares andaluces, de cierta notoriedad, hay que señalar que entre ellos se encuentran algunos de la talla de Luis Martín de la Plaza, de Antequera, la poetisa igualmente antequerana doña Cristobalina Fernández de Alarcón, que ob- 
tiene el primer premio en la modalidad de octavas, el ruteño Juan de Aguilar ${ }^{13}$, residente en la misma ciudad citada, y los gienenses Alonso de Bonilla y Juan de Barrionuevo y Moya ${ }^{14}$.

Menos interés tiene para nosotros, porque cae fuera de los límites cronológicos gongorinos, la relación de fiestas y certamen poético en honor de San Rafael (1653), que coleccionó don Pedro Mesía de la Cerda, pero hay también en ellos una poetisa, que bien pudiera tener alguna relación familiar con Góngora, doña Ana de Pineda Serrano y Góngora ${ }^{15}$, y un escritor gongorino relevante, Gabriel Bocángel Unzueta, entre muchos otros que sólo conocemos de nombre.

Todo ello nos hace vislumbrar una vida cultural subyacente de cierta actividad, no sólo por el acto en sí y por la transmisión de la crónica impresa, sino por la equiparación que supone ese aspecto de los certámenes cordobeses con otros celebrados en ciudades de mayor o parecida importancia. Nos parece que Góngora y los poetas de su círculo se convierten en elemento decisivo en alguna de las celebraciones, como la dedicada a la reina Margarita, en tanto que en otras se constata igualmente su presencia o su huella.

Pero además de este entramado cultural que se documenta en actos como los citados ${ }^{16}$, la urdimbre de la cultura cordobesa tiene otras muchas figuras de singular relieve, entre los que destacan Luis Carrillo y Sotomayor y Juan Rufo Gutiérrez, algo anteriores a don Luis de Góngora y en algún caso, como ocurre con el primero de los mencionados, considerado a veces un precedente en lo que se refiere a su manera de hacer poética.

La aportación de Luis Carrillo ha sido bien estudiada y editada ${ }^{17}$, al mismo tiempo que se conoce el lugar que ocupa en el panorama de las letras áureas. Más joven que Góngora y muerto prematuramente (había nacido en Baena, 1582, y falleció en el Puerto de Santa María, 1610), antes de que se difundiesen los poemas mayores gongorinos, su obra literaria fue editada póstumamente por su hermano Alonso (1611, con reedición corregida en 1613). En los preliminares de la obra encontramos dos composiciones de Quevedo, lo que puede resultar indicativo de que su poesía no pertenece al círculo de influencia gongorino. Su formación es eminentemente clásica, en la línea del humanismo aristotélico y senequista; tradujo un tratado de Séneca, De la brevedad de la vida, y los Remedios de amor, de Ovidio. (También su hermano Alonso parece interesado en temas de raíz estoica y cristiana, como se desprende de sus dos traducciones de San Ambrosio, una sobre la fugacidad del tiempo y la otra sobre la buena muerte). 
«Tanto por plumas...» Góngora y los poetas cordobeses...

En su colección Dámaso Alonso advirtió la frecuente presencia del mar; era Carrillo cuatralbo de las galeras de España. Entre sus poemas hay sonetos amorosos y morales, dos églogas piscatorias, hasta quince canciones en torno al amor no correspondido, en la línea petrarquista, décimas, romances y letrillas. Su obra más significativa es la «Fábula de Acis y Galatea», a menudo tratada en relación con la de Góngora sobre el mismo tema, pero anterior y bastante distinta, salvo en el tema de la fábula ovidiana y en el metro, además de la coincidencia en la dedicatoria al Conde de Niebla. No suele aceptarse que la composición sirviera de acicate o estímulo para que Góngora compusiera su Polifemo. Es posible que exista alguna afinidad entre ambos, sobre todo a partir del Libro de la erudición poética, en el que se propugna una lengua poética refinada, para pocos, que remite con frecuencia a modelos latinos.

En el terreno de la épica culta Juan Rufo viene acompañado de otros dos cordobeses que dan variedad a esa tendencia literaria tan cultivada en la época de Felipe II; son el lucentino Luis Barahona de Soto y el cordobés Gonzalo Gómez de Luque. Si Rufo en su Austriada ofrece un poema épico de rasgos marcadamente históricos, en torno a don Juan de Austria y la batalla naval de Lepanto, Barahona se inscribe en la órbita de la influencia ariostesca en España, con su poema Las lágrimas de Angélica, tan alabado por Cervantes, en tanto que Gómez de Luque, menos conocido y estudiado, ofrece una copiosa materia épica en verso, el Celidón de Iberia, muy influida por los libros de caballerías hispánicos pero con pretensiones de cierta originalidad ${ }^{18}$.

En el círculo inmediato gongorino hay que deslindar entre los sabios y eruditos y los propiamente poetas, aunque con alguna frecuencia encontramos escritores que participan de los dos campos. Sin duda, los más tempranos y mejores defensores o apologistas de los grandes poemas de Góngora y de su estilo son cordobeses y pertenecen al círculo de sus amigos más cercanos; son don Francisco Fernández de Córdoba (fallecido en Rute en 1626), más conocido por su cargo eclesiástico de Abad de Rute, y Pedro Díaz de Ribas.

$\mathrm{Al}$ Abad de Rute envía Góngora las Soledades un poco después que al humanista Pedro de Valencia, y su respuesta es un mediano y temprano comentario, titulado «Parecer de don Francisco de Córdoba acerca de las Soledades a instancias de su autor» (hacia 1614) ${ }^{19}$, en el que alaba al autor y su alto estilo, aunque hace algún reparo a la excesiva recurrencia a determinadas figuras, como el hipérbaton y la hipérbole. Sin embargo, su obra más importante en el terreno de 
las controversias en torno a Góngora es un extenso y complejo Examen del Antídoto (1615), en el que puntualiza y refuta los ataques que Juan de Jáuregui había lanzado contra el poeta cordobés y su creación en el Antídoto contra la pestilente poesía de las Soledades, panfleto compuesto hacia 1614. El Examen es posiblemente la defensa mejor organizada y profunda de la nueva poesía. Por otra parte, en el terreno del estricto humanismo y de la historia, al Abad de Rute se deben obras de gran prestigio, como la Didascalia multiplex, editada en 1615, y la Historia de la casa de Córdoba, que se ha transmitido manuscrita hasta nuestros días.

En Pedro Díaz de Ribas (1587-1653) admiraron sus contemporáneos, al igual que en don Francisco Fernández de Córdoba, su erudición y su formación clásica. Era también poeta, pero su obra está dedicada con preferencia a cuestiones arqueológicas cordobesas, como Piedra de Córdoba, que es dedicación al Emperador Constantino Máximo, ilustrada con explicaciones (Córdoba, 1624) De las antigüedades y excelencias de Córdoba (1625), o El Arcángel San Rafael, particular custodio y amparo de la ciudad de Córdoba (editada en 1681, pero escrita hacia 1650). Como poeta aparece en alguno de los certámenes mencionados antes, en tanto que en la polémica gongorina Díaz de Ribas es autor de unos Discursos apologéticos por el estilo del Polifemo y Soledades, obras poéticas del Homero de España, don Luis de Góngora y Argote (compuestos hacia 1616-1617), que se suelen considerar una réplica contra los escritos antigongorinos del sevillano Juan de Jáuregui, así como de unas tempranas Anotaciones y defensas (1615-1624) a los poemas mayores gongorinos, que lo convierten en uno de los primeros comentaristas de las obras de don Luis.

En el mismo orden, aunque con menor entidad se encuentran Antonio de las Infantas y Mendoza y Francisco Martínez Portichuelo; al primero se debe un breve escrito ${ }^{20}$, situado en los primeros tiempos de la polémica en torno a las Soledades, en tanto que el segundo es autor más tardío y dejó igualmente manuscrito un texto dentro de la controversia gongorina que se ha estudiado no hace mucho tiempo ${ }^{21}$. Como puede verse, la defensa y justificación de la nueva poesía es obra de eruditos cordobeses, y al respecto no hay que olvidar que el propio Pedro de Valencia, extremeño, uno de los humanistas más prestigiosos de su momento y defensor de la nueva poesía, fue tenido en alguna ocasión por cordobés.

Algo parecido le ocurre a Antonio de Paredes, de igual procedencia regional, y uno de los más delicados y sensibles seguidores del lírico cordobés. Su obra editada en Córdoba, a su muerte, como señalamos, 
«Tanto por plumas...» Góngora y los poetas cordobeses...

nos permite adivinar una red de relaciones de amistad, apoyo y defensa en torno a la nueva poesía. Nacido hacia 1590, quizás en Trujillo, fallece en Toledo en 1622, cuando se había trasladado allí en busca de unas pruebas para el hábito de San Juan, según nos informa su amigo don Pedro de Cárdenas. Su colección poética, titulada Rimas, se editó en Córdoba el mismo año de su muerte.

Es una colección breve, que incluye también composiciones de Cárdenas, y que está formada por sonetos, romances (la forma métrica más abundante), junto con algunas estancias, epístolas, silvas y letrillas. La poesía ofrece muchos elementos clásicos y mitológicos, que nos hablan de su fecunda erudición, y en ella está muy presente el tema pastoril y amoroso, en la línea petrarquista, con un tono suave y contenido. No podía faltar en su recopilación la fábula mitológica de raíz ovidiana, y así se nos ha conservado una «Fábula de Daphne y Apolo", de sólo catorce octavas, en la que son muy patentes los elementos gongorinos. Este caballero extremeño fue alabado por su presencia agradable y por su continuado trato con las musas por Miguel de Cervantes, en el Viaje del Parnaso ${ }^{22}$, y también Juan Rufo le dedicó algún elogio.

Junto a él figura el noble don Pedro de Cárdenas y Angulo, de tan atractiva personalidad. Sin entrar en la dilucidación, casi imposible por ahora, de la biografía del personaje, se puede indicar la existencia de una hipótesis que supone que la historia personal de este escritor cordobés subyace en la apasionada vida de uno de los personajes del Quijote, concretamente en Cardenio, cuyo nombre derivaría del apellido Cárdenas, que ha nacido en Córdoba, según Cervantes, «una ciudad de las mejores desta Andalucía» ${ }^{23}$, a la que viene, junto con el falso duque, «a ver y feriar unos muy buenos caballos que en mi ciudad había, que es madre de los mejores del mundo» ${ }^{24}$. Además, don Pedro de Cárdenas y Angulo ${ }^{25}$ fue amigo y protector de Góngora, depositario de los poemas gongorinos, encargado de llevar al humanista Pedro de Valencia, residente en Madrid, el Polifemo, y la primera versión de la Soledad primera, en la primavera de 1613, al que don Luis dedica dos composiciones, ambas relacionados con caballos y toros, una décima de 1611, titulada «A don Pedro de Cárdenas, de un caballo que le mató un toro» ${ }^{26}$, y el soneto de 1614, "A don Pedro dé Cárdenas en un encierro de toros» ${ }^{27}$; por otra parte sabemos que es poeta él mismo y autor de teatro, como puede verse en las Rimas (1622), de Antonio de Paredes y en otros lugares.

Era un hombre aficionado a los caballos, como muchos otros nobles de la época, tal como hemós indicado en otro lugar ${ }^{28}$, y de él nos dice una información coetánea, de 1609, que «es hombre mozo, de 
edad de veinte y cuatro años, ágil, que sabe y puede andar el caballo, $\mathrm{y}$ este testigo le ha visto $\mathrm{y}$ ve en ellos muy de ordinario y sabe que los tiene suyos propios» ${ }^{29}$.

En el mismo ambiente literario cordobés está inmerso José Pérez de Ribas. El atractivo de su obra nos parece obvio, aunque casi no haya suscitado el interés de los gongoristas ${ }^{30}$. Sin embargo, baste indicar que algunos de sus poemas se encuentran confundidos con los mismos de don Luis ya en las primeras ediciones del siglo XVII, que se le atribuye una defensa del escritor al que conocía y trataba personalmente y que coleccionó sus composiciones manuscritas; es precisamente en éste último volumen aludido donde se encuentran algunos textos manuscritos gongorinos auténticos de los pocos que han llegado hasta nosotros. El mismo códice que contiene las creaciones de Pérez de Ribas lleva en el lomo la indicación Obras de Góngora, aunque la calidad de ambos autores no resulta equiparable en casi ninguna ocasión.

En la portada actual del códice que contiene sus poesías, se dan diversas referencias biográficas y bibliográficas de Pérez de Ribas, obra del estudioso que un día poseyó el manuscrito, don Aureliano Fernández-Guerra y Orbe: «Poesías, del Licenciado José Pérez de Rivas Tafur, natural de Córdoba, galanteador y enamorado en Granada, en 1606; pretendiente luego en Madrid, favorecido del Conde de Gondomar, y discípulo y amigo de Góngora; premiado en la justa poética de Córdoba, cuando las fiestas a la beatificación de Santa Teresa, año de 1615; justador allí también, dos años adelante, cantando la Pureza de la Virgen, encomiador en 1625 de su pariente el historiador Pedro Díaz de Rivas; del corregidor D. Luis de Baeza, en 1630; censor de la versión que de la Utopía sacó a luz Medinilla en 1637; panegirista, en 1639, de la Historia de los Carrillos, escrita por D. Alonso Carrillo Laso de Guzmán; y a este tiempo era en Córdoba el poeta beneficiado en la parroquial de la Magdalena, así como en 1637 se firmaba Capellán Mayor del Cabildo de la Ciudad».

Parece que estos datos, no siempre completamente exactos, fueron ignorados por la mayor parte de los bibliógrafos que en alguna ocasión se ocuparon del poeta cordobés.

De las ciento treinta y tantas composiciones del manuscrito original, la mayoría están dedicadas a cantar a las flores y a la amada, oculta bajo diversos nombres poéticos, como Ardenia, Anarda, Lisi, Amarilis, Jacinta o Anfrisa. Este último es el apelativo más abundante, y de creer al texto se trataría de una dama que vivía en Granada, concretamente en la calle de Gracia, y que pasaba los veranos en una aldea cercana a la ciudad, Pulianas, a la que da nombre un arroyo. 
«Tanto por plumas...» Góngora y los poetas cordobeses...

Casi todas las intercadencias de la calentura de amor, que dirían los clásicos, se manifiestan en estos versos de acuerdo con la convención cortesana-petrarquesca aún vigente entre los líricos de nuestro Siglo de Oro; ni siquiera está ausente el hecho de que la dama objeto de la atención poética esté casada. En ocasiones los versos de José Pérez de Ribas recuerdan, además de a Góngora, a Francisco de Rioja y a Pedro Soto de Rojas en su insistencia floral y amorosa, y preludian de alguna manera los idilios pastorales y campestres que serán tan abundantes en la lírica del siglo XVIII.

No son casi nunca composiciones de mucho aliento; es decir, el poeta no se acerca a las Soledades, al Polifemo o al Panegírico para tomar su inspiración, sino a los poemas breves de tendencia octosilábica $\mathrm{y}$ en menor medida al verso endecasílabo, algo menos documentado. En este sentido hay en el códice numerosos romances, y también letrillas, romancillos, madrigales, décimas..., junto con algunos sonetos dedicatorios.

La parte biográfica externa rastreable (si la obra literaria se toma en este caso como reflejo de la realidad) nos habla de un viaje a Madrid por parte del autor, donde cae enfermo, del itinerario que une a Granada con Córdoba, en cuyo camino contempla el castillo de Luque, al que dedica un romance, de otro viaje a Málaga y de diversos sucesos personales similares, casi ninguno de gran trascendencia. Frente a las letras humanas, claramente dominantes en la colección, hay también ejemplos de temas religiosos, como el poema dedicado a la beatificación de Santa Teresa, un soneto que obtuvo el primer premio y que se nos ha transmitido también impreso en el certamen cordobés de 1615, en cuyo impreso se incluye igualmente un soneto de Góngora, (el dedicado a la Inmaculada Concepción). Hay asimismo una pequeña serie de villancicos navideños, alguno de ellos en portugués y otro en guineo, es decir, en el habla convencional de los negros en los textos literarios del Siglo de Oro. Casi todas las composiciones son serias, aunque lo irónico se documenta en cantidad mínima en una sátira contra las feas y en otra contra una dama muy pequeña.

Más joven que los poetas citados hasta aquí, pero también afín en determinadas obras a la tendencia gongorina y denostado por la crítica posterior por eso mismo, es el baenense Miguel Colodrero de Villalobos ${ }^{31}$, que al mismo tiempo parece ser también amigo de Lope de Vega y Pedro Soto de Rojas, o al menos estos poetas consagrados elogian sus versos en diversas composiciones preliminares, quizá debido a la protección del duque de Sessa que amparaba a Lope y a Colodrero, entre otros. 
Conocemos hasta cuatro obras editadas de este olvidado poeta, aunque en la última de ellas parece indicar que ha editado cinco: «Ésta que de mis obras impresas es a dos visos la quinta", señala en la dedicatoria al Conde de Cabra. Sus libros conocidos son los siguientes: Varias rimas, impreso en Córdoba, por Salvador de Cea Tesa, en 1629; El Alfeo y otros asuntos en verso, ejemplares algunos, impreso en Barcelona, por Sebastián y Jaime Metaud, en 1639; Golosinas del ingenio, editado en Zaragoza, por Pedro Lanaja, en 1642, y Divinos versos o cármenes sagrados, que vio la luz igualmente en Zaragoza, por los herederos de Pedro Lanaja, en 1656. Frente a estos datos reales, ignoramos prácticamente todo lo demás; la fecha de su nacimiento se sitúa en Baena, en 24 de mayo de 1608 fue bautizado en la Parroquia de San Bartolomé. La juventud del autor, que en el momento de la edición del libro Varias rimas no sobrepasaba apenas los veinte años, las palabras de aliento al mismo, así como su relación con Baena y su poderoso señor, son elementos que se reiteran en los escritos preliminares del mismo. La fogosa inexperiencia del poeta, su orgullo, un tanto inmotivado todavía, se advierten en el prólogo al lector, en el que señala: «soberbia tengo para decirte que hay en ellas [en sus obras] partes que te han de agradar» ${ }^{32}$. Claro que si a alguno le pareciesen malas, no se le da de ello un ardite, «de todos se me da -escribe- las coplas de mis romances, por no decir las de don Gaiferos».

La relevancia de los autores que respaldan al escritor es enorme en estos años iniciales del siglo XVII; nada menos que el gran Lope de Vega, que firma el parecer y añade un buen soneto en el que se refiere a «tu tierna y verde edad, tu luz primera / así tu patria y tu nobleza honora», "cuando amanece de tu ingenio el día», añade; el madrileño Juan Pérez de Montalbán, el prestigioso predicador José de Valdivielso, entonces capellán del serenísimo Infante Cardenal, que escribe «que a la cultura de la edad primera / apuesta luces y compite rosas»; el granadino Pedro Soto de Rojas o el cultísimo ruteño Juan de Aguilar, humanista en Antequera, que le dedica unos versos latinos.

Por lo que respecta al libro inicial de Colodrero, el más cercano al período que nos interesa en esta ocasión, en él no se advierte ordenación temática ni métrica demasiado fija, aunque tanto los temas como, en menor medida, los metros sean bastante variados. Junto a reflexiones morales aparecen referencias mitológicas, poemas a las rosas, habitualmente como símbolo de la fugacidad de la vida, en lo que Colodrero adquiere singular maestría o especial insistencia; entre estos poemas, circunscritos al presente libro, están los titulados «Rosa ultrajada», "Al deshojar de una rosa en una fuente», «Haciendo ejemplar 
de su amor a un arroyo a la vista de unas rosas», «Ofreciendo unas flores", etc.

De especial interés para nosotros es el soneto «A don Luis de Góngora, en alabanza de su Polifemo y Soledades» (p. 23), que quizás pudo conocer Góngora porque, según se desprende del último terceto, el poeta cordobés está aún vivo cuando se compone el texto, aunque había fallecido sólo dos años antes de la edición que nos ocupa. El texto señala: «Y en mereciendo luces pisar bellas / holocausten, venérenle su nombre, / hasta el fin de los siglos sea eterno», lo que viene a decir que cuando muera («en mereciendo luces pisar bellas», referencia a estar en el cielo, más allá de las estrellas, o luces bellas, como si las estuviera pisando), entonces su nombre será inmortal.

Con respecto a la Fábula de Polifemo y Galatea señala que «de Galatea, dulces crueldades, / cantadas mira en superior desvelo», en tanto que las Soledades le merecen un cuarteto completo: «Estas aquellas suspensión del suelo / cultas heroicamente Soledades, / donde en altas profundas variedades / siente imitada su armonía el cielo».

Ambas composiciones gongorinas guían en cierto sentido otras dos de Colodrero; la influencia de las Soledades se advierte en la extensa «Silva» (p. 49) pastoril y paisajística, y el Polifemo presta algunos tonos y metros a la «Fábula de Teseo y Ariadna» (p. 63). No faltan tampoco ejemplos de la poesía áulica o cortesana, igualmente cultivada por Góngora, en variadas composiciones dedicadas a su mecenas, el Duque de Sessa, y a sus familiares más directos.

Con relación a otros poemas de esta colección, como la «Fábula de Hipomenes y Atalanta» (p. 93), se puede señalar que recủerda lejanamente alguno de los romances de Píramo y Tisbe, de don Luis, aunque el sentido paródico y satírico no está muy marcado (sí lo está, en cambio, en la «Mentira pura de Baco y Erigone», incluido en $E l$ Alfeo), de la misma manera que la mediana serie de romances de Colodrero, unos veintidós poemas, casi todos amorosos y pastoriles, nos evocan algunos recursos gongorinos, aunque con tonos más bien desvaídos y mediocres. En conjunto, estamos ante una colección variada, en la que se advierten algunos rasgos prometedores, que luego se cumplirán en colecciones más maduras, como los Divinos versos, de 1656.

Algunos otros poetas cordobeses de este período, como Enrique Vaca de Alfaro ${ }^{33}$, Juan Páez de Valenzuela o Francisco de Leiva Aguilar, a los que se ha prestado menos atención, junto con muchos más pertenecientes a las diversas órdenes religiosas de la ciudad, nos configuran en conjunto un variopinto panorama de cierta densidad lírica, aunque 
poco atendido y definido por los escasos críticos que se han ocupado del tema. Otros escritores cordobeses, algo más tardíos, como los judaizantes Miguel de Barrios y José Penso de la Vega ${ }^{34}$, ofrecen también en sus creaciones diversos elementos procedentes del famoso paisano. Por otra parte, hay que señalar que los ecos de la creación gongorina no se pierden nunca definitivamente en Córdoba, sino que en casi todas las épocas hay cierta pervivencia del espíritu de don Luis, tanto en el campo de la creación literaria, (tal como se constata en la composición y edición de la Soledad tercera, de León y Mansilla ${ }^{354}$, ya en los albores del siglo XVIII), como en el ámbito de estudio de su figura y de su obra, que tiene lugar a lo largo del siglo XIX, con diversa fortuna.

De todo ello podemos destacar al menos una idea: la renovación poética emprendida por Góngora cayó en un terreno fértil inmediato, que estaba integrado por humanistas y poetas cordobeses, todos amigos, admiradores y seguidores de su tendencia, de tal manera que, aunque la relevancia de algunos de ellos en el panorama de las letras hispánicas no sea mucha, sobre todo por mal conocida, las primeras batallas culteranas adquieren un inequívoco tinte cordobés. Más tarde, y de manera progresiva, prácticamente todos los poetas barrocos van a continuar transitando, en mayor o menor medida, por la senda que abrió don Luis de Góngora, pero los flancos de ese camino y muchos de sus componentes han estado alentados y sustentados por humanistas y líricos cordobeses que contribuyeron a hacer gloriosa con sus plumas la ciudad que, según Góngora, lo fue también por la valiente espada de sus capitanes.

\section{Notas}

1 Luis de Góngora, Obras completas, ed. Juan e Isabel Millé, Madrid, Aguilar, 1976, 60 ed., p. 455. Todas las menciones de la obra de Góngora se toman de esta edición, salvo indicación contraria. Se señalan las páginas a continuación de la cita en el cuerpo del texto, cuando se trata de varias referencias continuadas.

2 Feliciano Delgado León, Poesía cordobesa del siglo I al XVII (Antología crítica), Córdoba, Monte de Piedad, 1982.

3 Nos referimos a la edición siguiente: Luis de Góngora, Kodoku, Hon-yaku, Hyoshaku (traducción y comentario de las Soledades de Luis de Góngora), ed., Saiko Yoshida, Tokyo, Chikuma-shobo, 1999.

4 Miguel de Cervantes, El ingenioso hidalgo Don Quijote de la Mancha, ed. Luis Andrés Murillo, Madrid, Castalia, 1978, p. 121.

5 Luis de Góngora, Obras completas, op. cit., p. 895, "Carta de don Luis de Góngora en respuesta de la que le escribieron". La cita completa: "Caso que fuera 


\section{«Tanto por plumas...» Góngora y los poetas cordobeses...}

error, me holgara de haber dado principio a algo; pues es mayor gloria en empezar una acción que consumarla».

6 La mayor parte de los estudios gongorinos de Dámaso Alonso son ahora de cómodo acceso en los volúmenes V, VI y VII de sus Obras completas, Madrid, Gredos, 1978, 1982 y 1984, respectivamente. En la misma línea de aportaciones fundamentales a la vida y a la obra de don Luis de Góngora hay que citar, entre otros, a Robert Jammes, La obra poética de Don Luis de Góngora y Argote, Madrid, Castalia, 1987, y la monumental edición de Luis de Góngora, Romances, ed. Antonio Carreira, Barcelona, Quaderns Crema, 1998.

7 Cfr. nuestro estudio «La prensa cordobesa en la celebración del centenario de Góngora (1927)», Boletín de la Real Academia de Córdoba, 127, julio-diciembre, 1994, pp. 119-139.

8 Luis de Góngora, Obras completas, op. cit., p. 909.

9 La mala situación económica favorece la recurrencia a la poesía áulica por parte del cordobés, como hemos puesto de relieve en nuestro estudio:«Góngora poeta áulico: la visita del Príncipe de Gales», en Saggi in onore di Giovanni Allegra, ed. Paolo Caucci Von Saucken, Perugia, Università degli Studi di Perugia, 1995, pp. 169-185.

10 José María Valdenebro y Cisneros, La imprenta en Córdoba. Ensayo bibliográfico, Madrid, Sucesores de Rivadeneyra, 1900, pp. 1-172.

11 Relación de las honras que se hicieron en la ciudad de Córdoba a la muerte de la serenísima Reina Nuestra Señora Doña Margarita de Austria que Dios haya. Dirigida al Excmo. Sr. Duque de Lerma. Impreso con licencia de don Juan de Guzmán, corregidor de ella. En Córdoba, por la viuda de Andrés Barrera, año de MDCXII (1612, grafía actualizada, en ésta y en las demás referencias a textos de la época).

12 «Relación breve de las fiestas que en la ciudad de Córdoba se celebraron a la beatificación de la gloriosa Patriarca Santa Teresa de Jesús, fundadora de la reformación de Descalzos y Descalzas Carmelitas. Con la justa literaria que en ella hubo y sermón que predicó el doctor Álvaro Pizaño de Palacios, canónigo de escriptura en la Santa Iglesia de Córdoba. Por el licenciado Juan Páez de Valenzuela, clérigo presbítero. Dirigida a Doña Francisca de Guzmán, marquesa del Carpio, señora de las villas de Adamuz y Per Abad. Año 1615. Con licencia. Impreso en Córdoba, por la viuda de Andrés Barrera que sea en gloria». Un análisis del certamen es el de José Romera Castillo, "Justa poética cordobesa en honor de Santa Teresa", Boletín de la Real Academia de Córdoba de Ciencias, Bellas Letras y Nobles Artes, LII, 1982, pp. 96-118. Además, del mismo José Romera Castillo, "Compendio literario en honor de Santa Teresa (Notas de historia literaria sobre justas poéticas y representaciones teatrales)», Teresa de Jesús. Studi Storico-letterari, Roma, Teresianum, 1983, pp. 193227.

13 Un buen estudio sobre el mismo es el de José María de la Torre, Juan de Aguilar, un humanista ruteño del siglo XVII, Rute, Imprenta García, 1997.

14 Sobre este escritor, cfr. nuestra aproximación: “Una comedia barroca de tema egabrense: El ángel cordobés y el grande abad de Cabra (1640), de Juan de Barrio-nuevo y Moya", en Jornadas de Historia. Actas del III Centenario del Instituto Colegio Aguilar y Eslava de Cabra, Cabra, Ilmo. Ayuntamiento, 1993, pp. 29-48.

15 Parece que esta escritora ha pasado completamente desapercibida para los críticos interesados en estos temas de poesía femenina, al menos no se encuentra citada en el volumen correspondiente de Manuel Serrano y Sanz, Apuntes de una biblioteca española de escritoras españolas, Madrid, Sucesores de Rivadeneyra, 1913, 
tomo II. Debido a la rareza del librito en el que colabora, Relación de las fiestas eclesiásticas y seculares que la muy noble y siempre leal ciudad de Córdoba ha hecho a su Ángel Custodio San Rafael, este año de MDCLI, y razón de la causa por la que se hicieron. Puestas en orden por D. Pedro Mesía de la Cerda, caballero de la orden de Alcántara, dedicados a la muy noble y siempre leal ciudad de Córdoba. En Córdoba, por Salvador de Cea Tesa, Año de 1653, incluimos un fragmento de su aportación, de no mala factura, en la que se advierte el gusto por los motivos mitológicos:

Cuando entre confusas sombras

Está agonizando el orbe

Con la imagen de la muerte

Que informa Morfeo torpe,

Cuando está dormido el día

Y hecha un Argos la noche,

En la luz de cada estrella

Tiene un ojo de oro insomne.

Cuando el silencio en tinieblas

Hurta a la lengua las voces

$\mathrm{Y}$ ligados los sentidos

Se suspenden sus acciones,

Rafael arcángel sacro,

Celestial hermoso Adonis,

Habla a Andrés de las Roelas,

Noble y santo sacerdote. (Ibid., ff. 77 r. y v., grafía actualizada).

16 Algún otro certamen parecido no se imprime en Córdoba aunque tuvo lugar en nuestra ciudad, como ocurre con la Justa poética a la pureza de la Virgen Nuestra Señora, celebrada en la parroquia de San Andrés de Córdoba, en quince de enero de 1617, Impreso en Sevilla, por Gabriel Ramos Bejarano, 1617 (Existe edición de José María Valdenebro y Cisneros, Sevilla, 1889, que es la que tenemos a la vista). En esta reunión poética está Enrique Vaca de Alfaro, don Pedro de Cárdenas y Angulo, José Pérez de Ribas, Antonio de Paredes, Pedro Díaz de Ribas, además de don Luis de Góngora, junto a otros poetas de los que tenemos menos noticias, como Francisco de Gálvez, Juan de Peñalosa y Sandoval, Andrés López de Robles, etc. Valdenebro en sus notas sigue haciendo todavía a Antonio de Paredes oriundo de Córdoba, ibid., p. 52; sobre otros confiesa su ignorancia; a propósito de Pedro Díaz de Ribas escribe que nació en Córdoba en 1587 y que murió en la misma ciudad a los 66 años de su edad, ibid., pp. 53-54.

17 Son importantes los estudios y ediciones de la profesora Angelina Costa: Luis Carrillo y Sotomayor, Poesías completas, ed. Angelina Costa, Madrid, Cátedra, 1984; Luis Carrillo y Sotomayor, Libro de la erudición poética, ed. Angelina Costa, Sevilla, Alfar, 1987. Sobre el mismo autor: Luis Carrillo y Sotomayor, Obras, ed. Rosa Navarro Durán, Madrid, Castalia, 1990.

18 Una somera aproximación a los mismos la hemos llevado a cabo en nuestra comunicación "La poesía épica en los autores cordobeses de la época de Felipe II", en las Jornadas sobre Córdoba en tiempos de Felipe II, organizadas por la Real Academia de Córdoba, celebradas en Córdoba del 30 al 31 de octubre de 1998 (en prensa).

19 Para la datación aproximada de los textos de la polémica gongorina, transmitidos manuscritos, tengo en cuenta el apéndice II, "La polémica de las Soledades (1613-1666)", en Luis de Góngora, Soledades, ed. Robert Jammes, Madrid, Castalia, 1994, p. 607 y ss 


\section{«Tanto por plumas...» Góngora y los poetas cordobeses...}

20 «Carta de don Antonio de las Infantas y Mendoza respondiendo a la que escribió a don Luis de Góngora en razón de las Soledades", en Ana Suárez Miramón, ed., La batalla en torno a Góngora, Barcelona, Antoni Bosch, 1978, pp. 45-53.

21 Cfr. Joaquín Roses, "La Apología en favor de don Luis de Góngora de Francisco Martínez de Portichuelo (Selección anotada e introducción)", Criticón, 55, 1992, pp. 91-130, así como el importante libro del mismo autor, Una poética de la oscuridad. La recepción crítica de las «Soledades» en el siglo XVII, London, Tamesis Book, 1994.

22 «Este es un caballero de presencia /agradable y que tiene de Torcato /el alma sin alguna diferencia; / de Don Antonio de Paredes trato, / a quien dieron las Musas sus amigas, /en tierna edad, anciano genio y trato", Miguel de Cervantes, Viaje del Parnaso, ed. Vicente Gaos, Madrid, Castalia, 1973, p. 72.

23 Miguel de Cervantes, El ingenioso hidalgo Don Quijote de la Mancha, ed. Luis Andrés Murillo, op. cit., p. 292.

24 Ibid., p. 295. La hipótesis tendría que examinarse a la vista del libro de Antonio de Paredes, Rimas, Córdoba, Salvador de Cea, 1622, en el que existen algunas composiciones de don Pedro de Cárdenas y Angulo, una de ellas escrita en colaboración con Paredes. Este poeta llama siempre Cardenio a don Pedro, por lo que hay que entender que ese sería su nombre poético: "Es la rosa, oh Cardenio amigo, aquella / que admiré de tus glorias ya testigo", f. 7 v. (grafía actualizada), este soneto "es respuesta de otro por los mismos consonantes", seguramente obra de Cárdenas; "Cuyo miedo negó a la musa mía, / oh mi Cardenio, el paso / del que sacro licor beber solía», f. 16 r. "Mira, Cardenio, mira que entre tantas / de Efire prendas bellas / no llores tierno lo que dulce cantas" f. 17 r. (ambos fragmentos en el poema titulado "Tercetos o epístola a don Pedro de Cárdenas y Angulo»); "Miraba aquél, que gozando / de Cardenio el culto albergue / es tan regalado amigo / como agradecido huésped", f. 20 r., en la composición "Romance I. Describe una heredad de don Pedro de Cárdenas y Angulo, que está en el término de las Posadas». Particular interés tiene al respecto el romance VII, en el que se indica: «Es pedazo de una comedia, que compusieron nuestro poeta y don Pedro de Cárdenas y Angulo, y por ser muy culto y elegante y andar ya suelto en algunos traslados, se imprime con las demás obras»; en él puede apreciarse una historia de amor desgraciado, que pudiera tomarse como una versión de la narración cervantina de Cardenio y Luscinda, y que termina con el verso "Mira si sé amar, Cardenion, f. 31 v. Por otra parte, Cervantes está mencionado en el prólogo de esta obra al referirse éste a Antonio de Paredes en el capítulo 2 del Viaje del Parnaso, ya citado; además es conocida la relación de Cervantes con Córdoba, por lo que, si hubo alguna historia amorosa en la juventud de don Pedro, el autor del Quijote pudo conocerla y quizás tenerla en cuenta al componer la historia de los enamorados de Sierra Morena.

25 Referencias modernas a este personaje en Joaquín Roses, «La Apología en favor de don Luis de Góngora de Francisco Martínez de Portichuelo (Selección anotada e introducción)", Criticón, op. cit., especialmente p. 97, nota 17, y en el libro del mismo Joaquín Roses, Una poética de la oscuridad. La recepción crítica de las "Soledades» en el siglo XVII, op. cit. Don Pedro era aficionado a los poemas de Antonio de Paredes, según indica el licenciado Andrés Jacinto del Águila, en la dedicatoria a este noble de las Rimas, op. cit., f. 1 r., y quizás depositario de muchos de ellos, al igual que ocurría con los de Góngora, al que nos parece alude el mismo licenciado Del Águila al decir en el prólogo al lector: «confirmóme este pensamiento [el de editar las obras de Paredes] ver que cada día se imprimen nuevas obras de paesía y que 
entre ellas son muy raras las que merezcan ser estimadas, y que los ilustres ingenios y hombres doctos de nuestros tiempos, que pudieran imprimir sus escritos con gloria de la nación, no permiten salgan a luz», f. $3 \mathrm{r}$.

26 Luis de Góngora, Obras completas, op. cit., p. 356.

27 Ibid., pp. 501-502. También el soneto 335, de la edición de Millé, parece está dedicado al mismo. Es de 1615 y se titula "A un caballero de Córdoba que estaba en Granada", ibid., pp. 503-504.

28 Cfr. Antonio Cruz Casado, "Caballos andaluces y toros de lidia: las Advertencias o preceptos de torear con rejón (1651), de D. Pedro Jacinto de Cárdenas y Angulo", en Actas de las I Jornadas de la Real Academia en Córdoba sobre El Caballo (Córdoba, 15 al 17 de diciembre de 1994), Córdoba, Excma. Diputación, 1995 [1996], pp. 127-137. La sugerencia de que don Pedro de Cárdenas y Angulo pudiera identificarse con don Pedro Jacinto de Cárdenas y Angulo, que apuntamos en p. 134 y ss., es errónea y hay que descartarla a la vista de la aportación de don José Valverde Madrid y don Joaquín Moreno Manzano, "El caballo, el Alcázar y el libro de don Pedro de Angulo», ibid., especialmente, pp. 114-115.

29 Apud Dámaso Alonso, «Lope, don Pedro de Cárdenas y los Cardenios», en Obras completas, Madrid, Gredos, 1972, III, p. 904.

30 Con todo, existen rigurosas aportaciones, tangenciales en cuanto se refiere a su obra literaria, que es preciso recordar; entre ellas están: Dámaso Alonso, "Puño y letra de don Luis en un manuscrito de sus poesías", Estudios y ensayos gongorinos, Obras completas, Madrid, Gredos, 1978 vol. V., pp. 463-472; Antonio Carreira, "La recepción de Góngora en el siglo XVII: un candidato a la autoría del Escrutinio", Estudios sobre Góngora, Córdoba, Excmo. Ayuntamiento/Real Academia, 1996, pp. 29-42. En esta modélica aportación se atribuye (creemos que con fundamento) a José Pérez de Ribas la autoría del «Escrutinio sobre las impresiones de las obras poéticas de don Luis de Góngora", que se encuentra en el Apéndice V de sus obras completas, cfr. Luis de Góngora y Argote, Obras completas, op. cit., pp. 1221-1231, y José Valverde Madrid, "El poeta gongorino José Pérez de Rivas", Boletín de la Real Academia de Córdoba, julio-diciembre, 1997, núm. 133, pp. 173-175, que señala documentalmente las fechas de nacimiento y de muerte del escritor: 1590-1651. Por nuestra parte, retomamos aquí algunas ideas y datos de nuestro trabajo: "En la nieve helada de un sueñon: José Pérez de Ribas, un poeta cordobés del círculo de Góngora", comunicación en la Real Academia de Córdoba, Día de Góngora, 23 de mayo de 1999 (en prensa).

31 Nos hemos ocupado de este escritor en: “Un seguidor de Góngora oriundo de Baena: Miguel Colodrero de Villalobos (1608-¿1660?)", en I Jornadas de la Real Academia de Córdoba sobre Baena, 13-14 de diciembre de 1999 (en prensa).

32 Miguel Colodrero de Villalobos, Varias rimas, Al Excelentísimo Señor Don Luis Fernández de Córdoba, Córdoba, Salvador de Cea Tesa, 1629, texto de los preliminares. Las restantes referencias de este libro mediante la indicación de página en el cuerpo del texto.

33 Referencias biográficas y bibliográficas a este escritor y a muchos otros autores cordobeses se encuentran en el libro de José Luis Escudero López, Córdoba en la literatura. Estudio bio-bibliográfico (Siglos XV al XVII). El Ms. de E. Vaca de Alfaro, Córdoba, Publicaciones de la Universidad, 1988.

34 Un estudio muy completo sobre estos autores es el de Harm den Boer, La literatura sefardí en Amsterdam, Madrid, Universidad de Alcalá, 1995. Una aportación nuestra sobre el segundo citado: "La obra literaria de José Penso de la Vega", en I 


\section{«Tanto por plumas...» Góngora y los poetas cordobeses...}

Jornadas de la Real Academia de Córdoba sobre Espejo, Córdoba, Real Academia de Córdoba-Ayuntamiento de Espejo, 1993, pp. 167-187.

35 Nos hemos ocupado de esta cuestión en "Algunas secuelas de las Soledades: del barroco tardío al 27", Boletín de la Real Academia de Córdoba, 125, julio-diciembre, 1993, pp. 183-194. 